\title{
The Electrodiagnosis of Ulnar Nerve Entrapment at the Elbow
}

\author{
Ralph Z. Kern
}

\begin{abstract}
Entrapment of the ulnar nerve at the elbow is the second most common focal peripheral neuropathy. Recent advances have facilitated the electrodiagnosis of this common nerve entrapment. The goals of electrodiagnosis are to localize ulnar nerve dysfunction, confirm that the disturbance is confined to the ulnar nerve, and assess the severity of ulnar nerve dysfunction. The goal of this review is to highlight the important advances in anatomy, neurophysiology and methodology that impact upon the electrodiagnosis of entrapment of the ulnar nerve at the elbow, illustrate the limits of electrodiagnosis, and discuss methodological issues that may be the subject of further study. Careful attention to elbow position, temperature, and conservative estimates of conduction block should be part of common practice. Awareness of anatomical variations in structural anatomy, anomalous innervation and fascicular arrangement of ulnar nerve fibers are required to interpret electrodiagnostic studies accurately. The most reliable finding is slowing of the ulnar acrosselbow motor nerve conduction velocity to less than $50 \mathrm{~m} / \mathrm{sec}$ while recording from the abductor digiti minimi muscle, and should be carefully interpreted in the presence of a polyneuropathy or other neurogenic process. Alternative techniques such as relative ulnar slowing in different ulnar nerve segments, use of alternative muscles, sensory and mixed nerve techniques provide complementary information, and like all nerve conduction studies are highly operator-dependent and should be used on a case by case basis. Recent studies have focused the electromyographer's attention on the use of shorter across-elbow segments $(2-5 \mathrm{~cm})$. This may offer a reasonable trade-off between sensitivity and measurement error and may result in improved electrodiagnosis.
\end{abstract}

RÉSUMÉ: Électrodiagnostic de la compression du nerf cubital au niveau du coude. La compression du nerf cubital au niveau du coude est la deuxième neuropathie périphérique focale la plus fréquente. Des progrès récents en facilitent l'électrodiagnostic. Les buts de l'électrodiagnostic sont de localiser la dysfonction du nerf cubital, de confirmer que l'atteinte est limitée au nerf cubital et d'évaluer la sévérité de la dysfonction du nerf cubital. Le but de cette revue est de souligner les progrès importants réalisés en anatomie, en neurophysiologie et dans les outils diagnostiques qui ont un impact sur l'électrodiagnostic de la compression du nerf cubital au niveau du coude, d'illustrer les limites de l'électrodiagnostic et de discuter des aspects méthodologiques qu'il serait intéressant d'explorer davantage. On doit porter une attention particulière à la position du coude et à sa température, et une estimation conservatrice du blocage de conduction doit faire partie de la pratique courante. L'interprétation des études électrodiagnostiques nécessite une connaissance des variantes anatomiques structurales, des innervations anormales et de l'arrangement fasciculaire des fibres du nerf cubital. Le signe le plus fiable est le ralentissement de la vitesse de conduction quand le nerf franchit le coude à moins de $50 \mathrm{~m} / \mathrm{sec}$ lors de l'enregistrement fait au niveau du muscle abducteur du petit doigt et devrait être interprété avec prudence en présence d'une polyneuropathie ou d'un autre processus neurogène. D'autres techniques comme le ralentissement cubital relatif dans différents segments du nerf cubital, l'utilisation d'autres muscles, des techniques pour les nerfs sensitifs et mixtes ajoutent une information complémentaire et, comme toutes les études de conduction nerveuse sont très dépendantes de l'opérateur, devraient être utilisées au cas par cas. Des études récentes ont attiré l'attention de l'électromyographiste sur l'utilisation de segments plus courts au niveau du coude $(2$ à $5 \mathrm{~cm})$, ce qui peut offrir un compromis raisonnable entre la sensibilité et l'erreur de mesure et peut améliorer l'électrodiagnostic.

Can. J. Neurol. Sci. 2003; 30: 314-319

Entrapment of the ulnar nerve at the elbow (UN-E) is the second most common focal peripheral neuropathy. ${ }^{1}$ Recent advances have facilitated the electrodiagnosis of this common nerve entrapment. The goals of electrodiagnosis are to localize ulnar nerve dysfunction, confirm that the disturbance is confined to the ulnar nerve, and assess severity of ulnar nerve dysfunction. The American Academy of Neurology (AAN) ${ }^{2}$ and the American Association of Electrodiagnostic Medicine (AAEM) ${ }^{3,4}$ have recently developed practice parameter statements. A detailed description of ulnar nerve anatomy, as well as the clinical manifestations, etiology and treatment of UN-E can be found in textbooks, ${ }^{5,6}$ recent reviews, ${ }^{7}$ and editorials,${ }^{8}$ and are beyond the scope of this review. The goal of this review is to highlight the important advances in anatomy, neurophysiology and methodology that impact upon the electrodiagnosis of UN-E, illustrate the limits of electrodiagnosis, and discuss methodological issues that may be the subject of further study.

From the Mount Sinai Hospital and the University Health Network; and the Division of Neurology, Department of Medicine, the University of Toronto, Toronto, Ontario Canada.

Received February 12, 2003. AcCePted in Final form May 12, 2003. Reprint requests to: Ralph Z. Kern, Mount Sinai Hospital, 431-600 University Ave., Toronto, Ontario, M5G 1X5 Canada. 


\section{METHODS}

A literature search was undertaken of computerized databases (PREMEDLINE and MEDLINE 1966-2002; Embase 19802002; HealthSTAR/Ovid Healthstar 1975-2002; and CINAHL 1982-2002), using the medical subject headings "ulnar neuropathy" and "diagnosis". Hand searches of "Muscle \& Nerve", "Neurology", "Annals of Neurology", "Journal of Neurology Neurosurgery and Psychiatry", as well as relevant review articles and textbooks yielded additional articles. In total, 395 references were identified and 67/395 that specifically addressed UN-E were selected for this review.

\section{Anatomic considerations}

A clear understanding of ulnar nerve anatomy and the various known anomalous innervation patterns are necessary to accurately diagnose UN-E. The selection of appropriate nerve stimulation sites, 'across elbow' nerve segment length and interpretation of needle electromyography (EMG) findings depends on awareness of the normal anatomic relationships of the ulnar nerve and upper extremity structures. In the upper arm, the ulnar nerve travels through the medial intermuscular septum (arcade of Struthers) and passes into the posterior compartment of the arm. It then travels adjacent to the medial head of the triceps before passing into the ulnar groove between the medial epicondyle and olecranon. As many as $10 \%$ of individuals possess an anomalous epitrochleoanconeus muscle or fibrous band spanning between the medial epicondyle and olecranon. ${ }^{9}$ The ulnar nerve then passes beneath the humeroulnar arcade formed by the aponeurotic arch of the flexor carpi ulnaris muscle and enters the cubital tunnel - there is considerable variability in the anatomic arrangement of this flexor retinaculum ${ }^{9}$ (Figure).

After traveling through the cubital tunnel, ${ }^{10}$ the ulnar nerve pierces the flexor carpi ulnaris muscle approximately 4

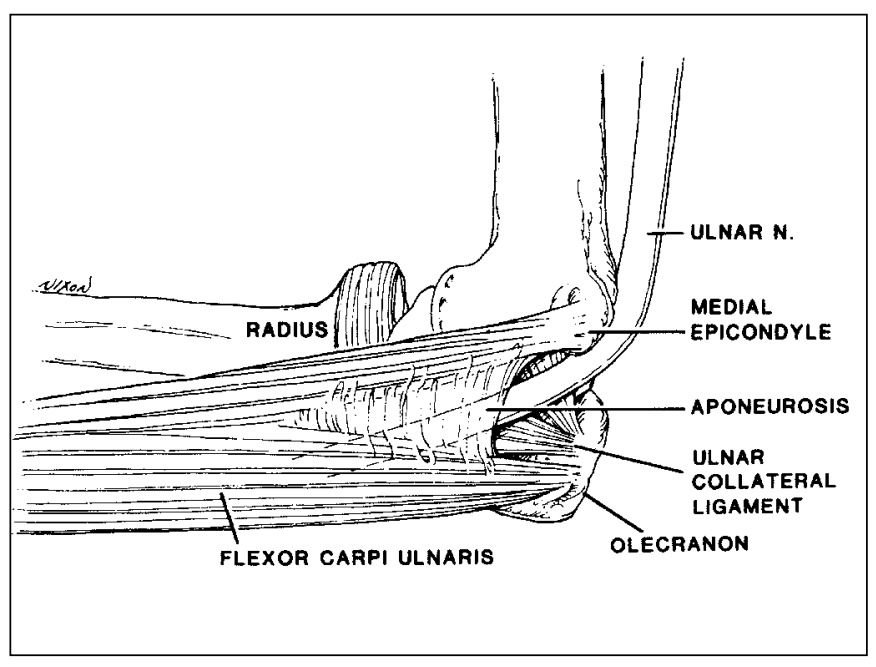

Figure: Ulnar nerve anatomy at the elbow. Entrapment may occur at the ulnar groove or more distally within the cubital tunnel. (Adapted with permission from Kincaid JC. AAEE minimonograph \# 31: the electrodiagnosis of ulnar neuropathy at the elbow. Muscle Nerve 1988; 11: 1005-1015. Copyright (C) 1988 Wiley Periodicals, Inc. Reprinted with permission of John Wiley \& Sons, Inc.) centimeters distal to the medial epicondyle (a potential site of entrapment $^{11}$ ) - this establishes a distal limit to below-elbow stimulation in across-elbow motor nerve conduction studies due to the deep location of the ulnar nerve. At the wrist, the ulnar nerve then passes through Guyon's canal (between the pisiform bone and the hook of the hamate) and divides into superficial and deep branches.

The ulnar nerve innervates two forearm muscles and most of the intrinsic hand muscles. Ulnar branches to flexor carpi ulnaris and the flexor digitorum profundus muscles usually arise at or below the elbow. Infrequently, the flexor carpi ulnaris branch arises proximal to the elbow and is spared in UN-E. ${ }^{12}$ The deep ulnar branch at the wrist supplies the hypothenar muscles, all the interossei, the third and fourth lumbricals, and the adductor pollicis muscle. The palmar and dorsal ulnar cutaneous sensory branches arise proximal to the wrist and supply sensation to the proximal ulnar border of the palm and dorsal ulnar sensory territories. The superficial terminal branch supplies the distal ulnar border of the palm and the palmar digital nerves that supply the fourth and fifth digits.

The dynamic anatomy of the ulnar nerve at the elbow ${ }^{13}$ is an important consideration in choosing elbow position in acrosselbow motor nerve conduction study (MNCS). When the elbow is flexed, the ulnar nerve may be compromised as the flexor carpi ulnaris aponeurosis tightens and decreases cubital tunnel volume, as the concave condylar groove flattens and as the medial head of the triceps pushes against the nerve posteriorly. ${ }^{13-}$ 15 Ultimately, the nerve may be stretched tightly around the medial epicondyle ${ }^{16}$ and may slide up to $1.4 \mathrm{~cm}$ distally or completely sublux out of its groove in many normal individuals. ${ }^{17}$ The nerve may be compressed at the edge of the humeroulnar arcade or within the cubital tunnel due to a rise in pressure with elbow flexion. ${ }^{18}$ In cubitus varus deformities the medial triceps muscle may displace the ulnar nerve over the medial epicondyle ${ }^{19}$ and this may contribute to UN-E. ${ }^{20,21}$

Anomalous innervation must be considered in the interpretation of ulnar MNCS and needle EMG. The MartinGruber anastomosis occurs in approximately $17 \%$ of the population $^{22}$ and consists of motor axons that travel with the median nerve at the elbow and cross to the ulnar nerve below the elbow to innervate the first dorsal interosseous and other ulnar innervated hand muscles. Occasionally the crossover will occur proximal to the site of below elbow stimulation and simulate conduction block. ${ }^{23}$ The Riches-Cannieu anastomosis is a rare anomaly in which anomalous motor responses may be recorded from the abductor pollicis brevis muscle following ulnar nerve stimulation at the wrist and elbow. ${ }^{24}$ In the presence of this anomalous innervation, the MNCS and needle EMG findings in $\mathrm{UN}-\mathrm{E}$ would require careful interpretation.

Fascicular involvement in ulnar neuropathy is a wellrecognized phenomenon. ${ }^{12,25}$ It explains the reported relative sparing of the flexor carpi ulnaris and dorsal ulnar cutaneous sensory fibers and preferential involvement of the first dorsal interosseous muscle in UN-E. Sunderland ${ }^{26}$ observed that the flexor carpi ulnaris and flexor digitorum profundus fibers occupied a deeper intraneural location than those innervating the intrinsic hand muscles. Appreciation of the selective vulnerability of ulnar nerve fascicles assists in the interpretation of UN-E diagnostic studies. 
Table: Summary of AAEM Practice Parameter Statement.

\section{Technical Issues}

- Monitor limb temperature

- Test other nerves if ulnar abnormal

- Specify elbow position (70-90 degrees)

- Avoid stimulation $>3 \mathrm{~cm}$ distal to medial epicondyle

- Exclude Martin-Gruber anastomosis

\section{Electrodiagnostic guidelines}

- Normal above elbow-below elbow MNCV $\geq 50 \mathrm{~m} / \mathrm{sec}$

- Normal across elbow-below elbow and below elbow-wrist MNCV difference $\leq 10$ $\mathrm{m} / \mathrm{sec}$

- Normal below elbow-above elbow CMAP amplitude reduction $\leq 20 \%$

- Temporal dispersion (no recommendation)

- Axilla-above elbow and above elbow-below elbow MNCV difference (no recommendation)

- Needle EMG should include study of first dorsal interosseous muscle

Abbreviations: MNCV - motor nerve conduction velocity; MNCS - motor nerve conduction study; CNAP - compound nerve action potential; CMAP - compound motor action potential.

\section{Practice parameter standards}

The AAEM and AAN practice parameter statements ${ }^{27,28}$ were jointly developed by the AAEM Quality Assurance Committee and the AAN Quality Standards Subcommittee in 1999. The recommendations are outlined in the Table.

\section{Methodological issues}

\section{a. Elbow position}

The AAEM standards recommend a 70-90 degree elbow position to provide the greatest correlation between surface skin measurement and true nerve length. ${ }^{29}$ The extended elbow position produces slower across elbow motor nerve conduction velocity $(\mathrm{MNCV})^{10}$ and in the evaluation of $\mathrm{UN}-\mathrm{E}$ has been shown to result in a lower ${ }^{30}$ or equivalent ${ }^{31}$ diagnostic sensitivity compared to the elbow flexed position. Kincaid et al ${ }^{32}$ suggested that the elbow flexed position produced less segment-to-segment MNCV variation than the elbow extended position.

\section{b. Length of across elbow segment}

The optimal across elbow segment length is a tradeoff between experimental error (specificity) and dilution of the abnormal 2-4 cm nerve segment ${ }^{33,34}$ by normal nerve (sensitivity). Straight forearm measurement distances of less than $10 \mathrm{~cm}$ may be associated with a $25 \%$ error in NCV estimates, ${ }^{35}$ which has been attributed in large part to latency error (using outdated nonelectronic latency identification methods). For an ulnar MNCV of $55 \mathrm{~m} / \mathrm{sec}$, Landau et $\mathrm{al}^{36}$ estimated errors for the below elbow-wrist and below elbowabove elbow segments of $3.6 \mathrm{~m} / \mathrm{sec}$ and $11.6 \mathrm{~m} / \mathrm{sec}$ respectively. Therefore the recommended above elbow-below elbow and below elbow-wrist MNCV difference of $10 \mathrm{~m} / \mathrm{sec}$ may result in a high false positive rate. Gert van Dijk et $\mathrm{al}^{37}$ used computer simulations to compare the $50 \mathrm{~mm}$ and $100 \mathrm{~mm}$ across elbow

\section{Practice options}

- First dorsal interosseous MNCS

- Flexor Carpi Ulnaris or Flexor Digitorum Profundus MNCS

- Short segment stimulation ('inching') study

- CNAP Study distances and calculated sensitivity and specificity estimates using receiver operator curve analysis. They found that area under the receiver operator curve was higher over the $50 \mathrm{~mm}$ distance despite a widening of the MNCV distribution. Furthermore, experimental error is magnified at higher MNCV values. In a previous study, Pridgeon and Campbell ${ }^{38}$ suggested a $40 \mathrm{~mm}$ across elbow segment length. Unfortunately, compression of the ulnar nerve as it exits the flexor carpi ulnaris muscle in the forearm may fall within the below elbow-wrist MNCV estimate in most cases. Based on anatomical considerations the region of interest spans approximately $80 \mathrm{~mm}$, longer than the optimal length of $50 \mathrm{~mm}$ and shorter than the recommended length of $100 \mathrm{~mm}$.

\section{c. Measurement of conduction block and short-segment incremental study}

Short-segment incremental studies are used in the electrodiagnosis of UN-E to identify the $1-2 \mathrm{~cm}$ segments where maximal conduction slowing and/or conduction block occurs. ${ }^{39-42}$ These studies rely on conduction block (in which measurement error is less important) or focal slowing to detect abnormalities. Azrielli et $\mathrm{al}^{43}$ have recently suggested that the measurement of latency change using $2 \mathrm{~cm}$ short-segment incremental study is more sensitive than measurement of conduction block or the use of routine across-elbow studies in the identification of UN-E. A minority of studies suggest that conduction block is more sensitive than focal slowing in the diagnosis of $\mathrm{UN}-\mathrm{E}^{44}$ and that it may be further improved through the use of regression equations. ${ }^{45}$ The definition of what constitutes an abnormal decline in compound motor action potentials (CMAP) amplitude or area remains controversial, ${ }^{46-49}$ with estimates as high as $50 \%$ in studies using computer simulations. ${ }^{50}$ The identification of conduction block in the ulnar nerve requires an appreciation of the effects of temperature, ${ }^{51}$ the double-hump configuration of 
the abductor digiti minimi $\mathrm{CMAP}^{52}$ anomalous innervation, ${ }^{23}$ and an awareness that conditions other than nerve compression may produce similar changes. ${ }^{53}$ It has been suggested by some authors, ${ }^{41,42}$ but not others, ${ }^{43}$ that conduction block is more likely to be seen in the first dorsal interosseous muscle. When using this muscle to record the ulnar CMAP, efforts should be made to eliminate an initial positive deflection in the first dorsal interosseous CMAP to avoid the effects of phase cancellation which may simulate conduction block.

Short-segment incremental studies may provide important clues to the site of compression in UN-E. A recent study by Hermann et $\mathrm{al}^{54}$ demonstrated the presence of conduction block proximal to the medial epicondyle in acute UN-E, contrary to the putative distal site of compression suggested in anatomic studies. $^{55} \mathrm{~A}$ study by Campbell et $\mathrm{al}^{56}$ using intraoperative electroneurography also suggested that most compression occurred proximal to the ME. Therefore, short-segment incremental studies appear to play an important role in the evaluation of UN-E, ${ }^{57}$ despite important methodological concerns, ${ }^{58}$ although the AAEM practice parameter statement lists this technique as optional.

\section{d. MNCV of different proximal and distal muscles}

Using needle EMG findings, Stewart et $\mathrm{al}^{25}$ suggested that the first dorsal interosseous is preferentially affected in UN-E. Ulnar MNCS recorded from the first dorsal interosseous muscle may have a higher sensitivity than traditional studies involving the abductor digiti minimi muscle,,$^{59}$ although other studies have not confirmed this observation. ${ }^{42,60}$ Other investigators have suggested that ulnar MNCV may be recorded from the flexor carpi ulnaris ${ }^{61}$ or flexor digitorum profundus ${ }^{62}$ muscles and used to localize abnormalities in UN-E. The sensitivity of these alternative techniques in UN-E has been studied by Tackmann and co-workers. ${ }^{60}$ Using the flexed elbow position and recording MNCV from the abductor digiti minimi, first dorsal interosseous and flexor carpi ulnaris muscles, they found equal involvement of fibers innervating the first dorsal interosseous and abductor digiti minimi muscles, and found flexor carpi ulnaris MNCV superior to the MNCV recorded from the flexor digitorum profundus muscle.

\section{e. Absolute vs. relative MNCV slowing across the elbow}

Most studies have demonstrated that an absolute reduction in ulnar MNCV across the elbow $\leq 50 \mathrm{~m} / \mathrm{sec}$ is more sensitive than a relative reduction of $\geq 10 \mathrm{~m} / \mathrm{sec}$, compared to the below elbowwrist segment. ${ }^{31,36,37,63}$ This may relate to a compounding of measurement error, operator-dependent technical difficulties, or axonal dysfunction distal to the site of entrapment. Due to significant measurement error and high variation, comparison of the axilla-above elbow and above elbow-below elbow segments is of lesser utility.

\section{f. Sensory studies}

Segmental compound nerve action potentials have been recorded in a small number of subjects with $U N-E^{64,65}$ and a comparison to conventional ulnar techniques has not been reported. The use of near-nerve recording of ulnar sensory nerve action potentials has been reported to effectively differentiate epicondylar from cubital tunnel compression. ${ }^{66}$ However, the studies are invasive, lengthy and have not been compared to conventional methods. It has been suggested that conventional ulnar sensory studies may be more sensitive than motor studies in early UN-E in which only sensory fibers are involved, ${ }^{42}$ however recent studies suggest that MNCS are more likely to be abnormal. ${ }^{43}$ Sensory abnormalities are much more prevalent (73\% vs. $11 \%)$ in the presence of ulnar MNCV slowing. ${ }^{67}$ In general, sensory conduction abnormalities in UN-E do not localize the lesion to the elbow segment and may not differentiate UN-E from other conditions such as thoracic outlet syndrome. ${ }^{60}$ The presence of dorsal ulnar cutaneous sensory abnormalities does help localize the abnormality proximal to the wrist and may assist in excluding ulnar nerve compression in Guyon's canal. Therefore, the use of these methods may complement conventional MNCS and should be viewed as optional techniques, as they are highly operator dependent.

\section{g. Needle EMG}

Needle EMG studies are important to exclude more proximal disturbances such as thoracic outlet syndrome, brachial plexopathies and cervical radiculopathies. The EMG may show greater involvement of the first dorsal interosseous muscle, and abnormalities in the flexor carpi ulnaris and flexor digitorum profundus muscles support ulnar nerve dysfunction proximal to the mid forearm. The motor Tinel's sign (EMG activity provoked by ulnar nerve percussion) has been the subject of a recent report. ${ }^{68}$ Motor nerve conduction study may be technically difficult in patients who have severe axonal dysfunction - in this context EMG evaluation of ulnar innervated muscles may be the only source of information about the affected distal hand muscles. As is the case with sensory studies, EMG evidence is of limited value in localizing ulnar nerve disturbances to the elbow segment.

\section{CONCLUSIONS AND RECOMMENDATIONS}

Entrapment of the ulnar nerve at the elbow is common and electrodiagnosis may successfully localize the electrophysiological abnormality to the elbow segment. The most reliable finding is slowing of the ulnar across-elbow MNCV to less than $50 \mathrm{~m} / \mathrm{sec}$ while recording from the abductor digiti minimi muscle, and should be carefully interpreted in the presence of a polyneuropathy or other neurogenic process. Alternative techniques such as relative ulnar slowing in different ulnar nerve segments, use of alternative muscles, sensory and mixed nerve techniques provide complementary information, and like all nerve conduction studies are highly operator-dependent and should be used on a case by case basis. Recent studies have focused the electromyographer's attention on the use of shorter across-elbow segments $(2-5 \mathrm{~cm})$. This may offer a reasonable tradeoff between sensitivity and measurement error and may result in higher diagnostic yields.

Careful attention to elbow position, temperature, and conservative estimates of conduction block should be part of common practice. Awareness of anatomical variations in structural anatomy, anomalous innervation and fascicular arrangement of ulnar nerve fibers are required to interpret electrodiagnostic studies accurately.

Electrodiagnosis should always be an extension of the clinical examination and interpreted in light of the observed clinical phenomena. Used appropriately in this fashion, electrodiagnosis 
is an essential tool in the diagnosis of UN-E. Future clinical studies should examine the relationship between electrophysiological findings and clinical outcomes in UN-E.

\section{ACKNowledgments}

Thanks to Shirley Rogers for technical assistance, John D. Stewart for his helpful comments, and to Patricia Davison for editorial assistance in the preparation of this manuscript.

\section{REFERENCES}

1. Miller RG. Ulnar Nerve Lesions. In: Brown WF, Bolton CF, (Eds). Clinical Electromyography. Stoneham, MA: Butterworths, 1987.

2. Campbell WW, Carroll DJ, Greenberg MK, et al. Practice parameter: electrodiagnostic studies in ulnar neuropathy at the elbow. Neurology 1999; 52: 688-690.

3. Campbell WW, Carroll DJ, Greenberg MK, et al. The electrodiagnostic evaluation of patients with ulnar neuropathy at the elbow: literature review of the usefulness of nerve conduction studies and needle electromyography. Muscle Nerve 1999; 22: S175-S205.

4. Campbell WW, Carol DJ, Greenberg MK, et al. Practice parameter for electrodiagnostic studies in ulnar neuropathy at the elbow: summary statement. Muscle Nerve 1999; 22: 408-411.

5. Stewart JD. Focal Peripheral Neuropathies. 3rd ed. Philadelphia, PA: Lippincott, Williams and Wilkins, 2000.

6. Dawson DM, Hallett M, Wilbourn AJ, et al. Entrapment Neuropathies. 3rd ed. Philadelphia, PA: Lippincott, Williams, and Wilkins, 1998.

7. Bradshaw D, Shefner J. Ulnar neuropathy at the elbow. Neurol Clin 1999; 17: 447-461.

8. Campbell W. Ulnar neuropathy at the elbow. Muscle Nerve 2000; 23: 450-452.

9. Campbell W. Variations in anatomy of the ulnar nerve at the cubital tunnel: pitfalls in the diagnosis of ulnar neuropathy at the elbow. Muscle Nerve 1991; 14: 733-738.

10. Kincaid JC. AAEE minimonograph \# 31: the electrodiagnosis of ulnar neuropathy at the elbow. Muscle Nerve 1988; 11: $1005-1015$.

11. Campbell WW, Pridgeon RM, Sahni KS. Entrapment neuropathy of the ulnar nerve at its point of exit from the flexor carpi ulnaris muscle. Muscle Nerve 1986; 11: 467-470.

12. Campbell WW, Pridgeon RM, Riaz G, et al. Sparing of the flexor carpi ulnaris in ulnar neuropathy at the elbow. Muscle Nerve 1989; 12: 965-967.

13. Apfelberg DB, Larson SJ. Dynamic anatomy of the ulnar nerve at the elbow. Plast Reconstr Surg 1973; 51: 76-81.

14. Green JR, Rayan GM. The cubital tunnel: anatomic, histologic, and biomechanical study. J Shoulder Elbow Surg 1999; 8: 466-470.

15. O'Driscoll SW, Horii E, Carmichael SW, et al. The cubital tunnel and ulnar neuropathy. J Bone Joint Surg 1991; 73B: 613-617.

16. Gelberman RH, Yamaguchi K, Hollstein SB, et al. Changes in interstitial pressure and cross-sectional area of the cubital tunnel and of the ulnar nerve with flexion of the elbow: an experimental study in human cadavera. J Bone Joint Surg Am 1998; 80: 492-501.

17. Childress H. Recurrent ulnar nerve dislocation at the elbow. Clin Orthop 1975; 108:168-173.

18. Werner CO, Olin P, Elmqvist D. Pressures recorded in ulnar neuropathy. Acta Orthop Scand 1985; 56: 404-406.

19. Spinner RJ, O'Driscoll SW, Davids JR, et al. Cubitus varus associated with dislocation of both the medial portion of the triceps and the ulnar nerve. J Hand Surg 1999; 24A: 718-726.

20. Spinner RJ, Goldner RD. Snapping of the medial head of the triceps: diagnosis and treatment. Techniques in Hand \& Upper Extremity Surgery 2002; 6: 91-97.

21. Spinner RJ, O'Driscoll SW, Jupiter JB, Goldner RD. Unrecognized dislocation of the medial portion of the triceps: another cause of failed ulnar nerve transposition. J Neurosurg 2000; 92: 52-57.

22. Leibovic SJ, Hastings H. Martin Gruber revisited. J Hand Surg 1992; 17A: 47-53
23. Marras C, Midroni G. Proximal Martin-Gruber Anastomosis mimicking ulnar neuropathy at the elbow. Muscle Nerve 1999; 22: 1132-1135.

24. LoMonanco M. Padua L, Gregori B, et al. Ulnar innervation of the thenar eminence with preservation of median innervation of the first lumbrical muscles. Muscle Nerve 1997; 20: 629-630.

25. Stewart J. The variable clinical manifestations of ulnar neuropathies at the elbow. J Neurol Neurosurg Psychiatry 1987; 50: 252-258.

26. Sunderland S. Intraneural topography of radial, median, and ulnar nerves. Brain Nerve 1945; 68: 243-299.

27. Campbell W. The electrodiagnostic evaluation of patients with ulnar neuropathy at the elbow: literature review of the usefulness of nerve conduction studies and needle electromyography. Muscle Nerve 1999; 22: S175-S205.

28. Practice parameter for electrodiagnostic studies in ulnar neuropathy at the elbow: summary statement. Arch Phys Med Rehabil 1999; 80: 357-359.

29. Checkles N, Russakov A, Piero D. Ulnar nerve conduction velocityeffect of elbow position on measurement. Arch Phys Med Rehabil 1970:362-365.

30. Kothari M, Preston D. Comparison of the flexed and extended elbow positions in localizing ulnar neuropathy at the elbow. Muscle Nerve 1995; 18: 336-340.

31. Bielawski M, Hallett M. Position of the elbow in determination of abnormal motor conduction of the ulnar nerve across the elbow. Muscle Nerve 1989; 12: 803-809.

32. Kincaid JC, Phillips IL, Daube JR. The evaluation of suspected ulnar neuropathy at the elbow. Normal conduction study values. Arch Neurol 1986; 43: 44-47.

33. Britz G, Haynor D, Kuntz C, et al. Ulnar nerve entrapment at the elbow: correlation of magnetic resonance imaging, clinical, electrodiagnostic, and intraoperative findings. Neurosurgery 1996; 38: 458-465.

34. Brown WF, Yates SK. Percutaneous localization of conduction abnormalities in human entrapment neuropathies. Can J Neurol Sci 1982; 9: 391-400.

35. Maynard FM, Stolov WC. Experimental error in determination of nerve conduction velocity. Arch Phys Med Rehabil 1972; 53: 362-372.

36. Landau M, Diaz M, Barner K, Campbell W. Changes in nerve conduction velocity across the elbow due to experimental error. Muscle Nerve 2002; 26: 838-840.

37. Gert van Dijk J, Meulstee J, Zwarts M, Spaans F. What it the best way to assess focal slowing of the ulnar nerve? Clin Neurophysiol 2000; 112: 286-293.

38. Pridgeon RM, Campbell WW. Evaluating focal neuropathies: the long and short of it. Muscle Nerve 1991; 14: 881-882.

39. Miller R. The cubital tunnel syndrome: diagnosis and precise localization. Ann Neurol 1979; 6: 56-59.

40. Kanakamedala R, Simons D, Porter R, Zucker R. Ulnar nerve entrapment at the elbow localized by short segment stimulation. Arch Phys Med Rehabil 1988; 69: 959-963.

41. Campbell WW, Pridgeon RM, Sahni KS. Short-segment incremental studies in the evaluation of ulnar neuropathy at the elbow. Muscle Nerve 1992; 15: 1050-1054.

42. Payan J. Electrophysiological localization of ulnar nerve lesions. J Neurol Neurosurg Psychiat 1969; 32: 208-220.

43. Azrielli Y, Weimer L, Lovelace R, Gooch C. The utility of segmental nerve conduction studies in ulnar neuropathy at the elbow. Muscle Nerve 2003; 27: 46-50.

44. Pickett JB, Coleman LL. Localizing ulnar nerve lesions to the elbow by motor conduction studies. Electromyogr Clin Neurophysiol 1984; 24: 343-360.

45. Pickett J. The use of regression equations in the localization of ulnar and peroneal nerve lesions. Electromyogr Clin Neurophysiol 1984; 24: 361-368.

46. Schulte-Mattler W, Muller T, Georgiadis D, et al. Length dependence of variables associated with temporal dispersion in human motor nerves. Muscle Nerve 2001; 24: 527-533.

47. Olney RK, Miller RG. Conduction block in compression neuropathy: recognition and quantification. Muscle Nerve 1984; 7: 662-667. 
48. Taylor PK. CMAP dispersion, amplitude decay and area decay in a normal population. Muscle Nerve 1993; 16: 1181-1187.

49. Weber F. Conduction block and abnormal temporal dispersiondiagnostic criteria. Electromyogr Clin Neurophysiol 1997; 37: 305-309.

50. Rhee EK, England JD, Sumner AJ. A computer simulation of conduction block: effects produced by actual block versus interphase cancellation. Ann Neurol 1990; 28: 146-156.

51. Rutkove S, Geffroy M, Lichtenstein S. Heat-sensitive conduction block in ulnar neuropathy at the elbow. Clin Neurophysiol 2001; 112: 280-285.

52. Kern RZ, Alex A. Reference electrode contribution to the ADM CMAP (Abstract). Can J Neurol Sci 1993; 20(suppl 2): S53.

53. McCluskey L, Feinberg D, Cantor C, Bird S. "Pseudo-conduction block" in vasculitic neuropathy. Muscle Nerve 1999; 22: 13611366.

54. Hermann DN, Preston DC, McIntosh KA, Logigan EL. Localization of ulnar neuropathy with conduction block across the elbow. Muscle Nerve 2001; 24: 698-700.

55. Contreras M, Warner M, Charbonneau WJ. Anatomy of the ulnar nerve at the elbow: potential relationship of acute ulnar neuropathy to gender differences. Clin Anatomy 1998; 11: 372-378.

56. Campbell WW, Sahni SK, Pridgeon RM, et al. Intraoperative electroneurography: management of ulnar neuropathy at the elbow. Muscle Nerve 1988; 11: 75-81.

57. Campbell W. The value of inching techniques in the diagnosis of focal nerve lesions. Muscle Nerve 1998; 21: 1554-1556.

58. Geiringer S. Inching techniques are of limited value. Muscle Nerve 1998; 21: 1557-1558.
59. Kothari M, Heistand M, Rutkove SB. Three ulnar nerve conduction studies in patients with ulnar neuropathy at the elbow. Arch Phys Med Rehabil 1998; 79: 87-89.

60. Tackmann W, Vogel P, Kaeser H, Ettlin T. Sensitivity and localizing significance of motor and sensory electroneurographic parameters in the diagnosis of ulnar nerve lesions at the elbow. J Neurol 1984; 231: 204-211.

61. Benecke R, Conrad B. The value of electrophysiological examination of the flexor carpi ulnaris muscle in the diagnosis of ulnar nerve lesions at the elbow. J Neurol 1980; 223: 207-217.

62. Felsenthal G, Brockman PS, Mondell DL, Hilton EB. Proximal forearm ulnar nerve conduction techniques. Arch Phys Med Rehabil 1986; 67: 440-444.

63. Kern RZ, Alex AA. Quantitative CMAP analysis in ulnar neuropathy (Abstract). Muscle Nerve 1994; 17: 1087.

64. Lo Y, Dan Y, Lee M, Ratnagopal P. Segmental mixed nerve conduction studies in ulnar neuropathy at the elbow. J Clin Neurophysiol 2001; 18: 456-459.

65. Merlevede K, Theys P, van Hees J. Diagnosis of ulnar neuropathy: a new approach. Muscle Nerve 2000; 23: 478-481.

66. Odabasi Z, Oh SJ, Claussen GC, Kim DS. New near-nerve needle nerve conduction technique: differentiating epicondylar from cubital tunnel ulnar neuropathy. Muscle Nerve 1999; 22: 718723.

67. Bhala R. Electrodiagnosis of ulnar nerve lesions at the elbow. Arch Phys Med Rehabil. 1976; 57: 206-212.

68. Montagna P, Liguori R. The motor Tinel sign: a useful sign in entrapment neuropathy? Muscle Nerve 2000; 23: 976-978. 